\section{World nuclear security gets welcome boost}

An international initiative to help safeguard nuclear materials worldwide was announced on 30 September. The World Institute for Nuclear Security plans to do for nuclear security what the World Association of Nuclear Operators, created in the aftermath of the 1986 Chernobyl powerplant accident, does for nuclear safety.

The institute will bring together nuclear players, including scientific experts, to share sensitive information. Its goal is to strengthen accounting, control and physical protection of nuclear materials and facilities worldwide. The group, to be based

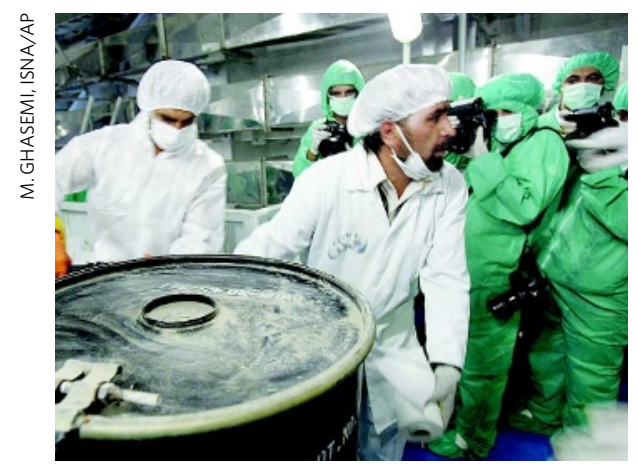

Better safeguards are planned for nuclear material. in Vienna, is the brainchild of the Nuclear Threat Initiative group in Washington DC, co-chaired by former senator Sam Nunn and broadcast mogul Ted Turner. Roger Howsley, former director for security at British Nuclear Fuels, will be executive director.

\section{South Africa replaces its health minister}

African National Congress member Barbara Hogan took over last week as South Africa's health minister. She replaces the controversial Manto Tshabalala-Msimang, who had sparked international outrage by proposing that HIV be treated with garlic and beetroot.

AIDS activists welcomed the appointment, made by the government of new president Kgalema Motlanthe. Hogan is on the advisory board of the Amandla AIDS Fund, which provides grants for HIV/AIDS prevention and treatment programmes.

But the South African parliament also quietly passed a law that gives the minister sweeping authority over the approval of new medicines and a remit to regulate traditional medicines alongside conventional pharmaceuticals. The bill created a body - the South African Health Products Regulatory Authority - to oversee the approval of medicines.

Crucially, the agency's chief executive, who will be appointed by the health minister, will be accountable not to a board, as the existing Medicines Control Council is, but only to the minister. Critics of the bill fear that it may lead to conflicts of interest in the public-health system, and that it risks diluting the scientific basis behind making new treatments available.

For a longer version of this story, see http:// tinyurl.com/4hh928.

\section{Falcon rocket reaches low-Earth orbit}

It was fourth time lucky for Space Exploration Technologies and its Falcon 1 rocket. After a trio of failed flights since 2006, the privately funded rocket soared into lowEarth orbit from Kwajalein atoll on Omelek Island on 28 September.

SpaceX and its founder, Elon Musk, hope that the launch marks the dawn of a new, substantially cheaper era of space flight. The company estimates that each Falcon-1 launch will cost less than US $\$ 10$ million; existing systems can cost up to four times as much.

Next up are the company's larger heavylift rockets. Dubbed Falcon 9 and Falcon 9 Heavy, these rockets could potentially carry 